\title{
Intravenous injection of low-dose flurbiprofen axetil for preventing post-ERCP pancreatitis in high-risk patients: An interim analysis of the trial
}

Authors

Institution
Yuji Fujita, Sho Hasegawa, Yuri Kato, Ken Ishii, Akito Iwasaki, Takamitsu Sato, Yusuke Sekino, Kunihiro Hosono, Atsushi Nakajima, Kensuke Kubota

Department of Gastroenterology and Hepatology, Yokohama City University School of Medicine, Yokohama, Japan submitted

25. September 2015 accepted after revision 29. July 2016

\section{Bibliography}

DOI http://dx.doi.org/

10.1055/s-0042-115172

Published online: 21.9.2016

Endoscopy International Open

2016; 04: E1078-E1082

(c) Georg Thieme Verlag KG

Stuttgart - New York

E-ISSN 2196-9736

\section{Corresponding author}

Kensuke Kubota

Phone: 81457872800

Fax: +81457872866

kubotak@yokohama-cu.ac.jp
Background and study aims: Several meta-analyses and randomized control trials have demonstrated the efficacy of rectal nonsteroidal anti-inflammatory drugs for preventing post-endoscopic retrograde cholangiopancreatography (ERCP) pancreatitis (PEP). Diclofenac or indomethacin was administered at a dose of $100 \mathrm{mg}$ in those studies, which may be too high for Asian population. In addition, rectal administration can be considered complicated.

Patients and methods: This study was a prospective, randomized, placebo-controlled trial. Patients with a PEP risk score $\geq 1$ were randomly assigned to receive intravenous injection of $50 \mathrm{mg}$ flurbiprofen axetil (flurbiprofen group) or saline only (placebo group). The primary outcome was reduced PEP. The secondary outcome was amylase

\section{Introduction}

$\nabla$

Acute pancreatitis is the most common adverse event (AE) associated with endoscopic retrograde cholangiopancreatography (ERCP). Post-ERCP pancreatitis (PEP) occurs in $1 \%$ to $10 \%$ of patients [1-3], and in $17 \%$ to $40 \%$ of high-risk patients [4-6]. Most cases of PEP are mild or moderate, but severe pancreatitis, including that requiring endoscopic intervention, occurs in $0.4 \%$ to $0.6 \%$ of those cases $[7,8]$. Nonsteroidal anti-inflammatory drugs (NSAIDs) are inhibitors of phospholipase $\mathrm{A} 2$, which is believed to have a pivotal role in the initial inflammatory cascade of acute pancreatitis [9-11]. Several randomized controlled trials [12-15] have confirmed the efficacy of rectal NSAIDs for prevention of PEP. However, in those studies, diclofenac or indomethacin was used at a dose of $100 \mathrm{mg}$, which is higher than the usual dose in Asia; furthermore, rectal administration may be considered complicated. Intravenous injection of NSAIDs is technically easy for patients. It is desirable to minimize the dose of NSAIDs because of potent side effects [6]. There- level after 2 hours of ERCP as a predictor of PEP. (Clinical Trials.gov, ID UMIN000011322)

Results: In total, 144 patients were enrolled from August 2013 to March 2015. We performed an interim analysis of the first 100 patients: 47 received flurbiprofen axetil and 53 received placebo. PEP occurred in 11 patients (11\%): 2 of $47(4.3 \%)$ in the flurbiprofen group and 9 of 53 (17\%) in the placebo group $(P=0.042)$. Relative risk reduction was $62.4 \%$. Hyperamylasemia did not differ significantly ( $17.0 \%$ vs. $26.4 \%, P=0.109$ ). This analysis resulted in early termination of the study for ethical reasons.

Conclusions: Intravenous injection of low-dose flurbiprofen axetil after ERCP can reduce the incidence of PEP in high-risk patients

fore, we conducted a randomized controlled clinical trial to evaluate the efficacy and safety of intravenous injection of low-dose flurbiprofen axetil for preventing PEP in high-risk patients.

\section{Patients and methods}

$\nabla$

\section{Study design}

This study was prospective, randomized, and placebo-controlled. It was approved by the Institutional Review Boards before initiation of the study, and was registered (ClinicalTrials.gov, ID UMIN000011322).

\section{Patients}

Patients who were scheduled to undergo ERCP were included. All patients had a PEP risk score of $\geq 1$ in a previous study $[6,16]$ ( Table 1 ). Patients were excluded for any of the following reasons: (1) acute or active pancreatitis; (2) metallic stent inserted across the papilla; (3) history of endoscopic sphincterotomy; (4) peptic ulcer diseases; (5) aspirin-induced asthma; (6) NSAIDs during the 
Table 1 Major and minor study inclusion criteria used to calculate PEP risk score.

\begin{tabular}{|l|l|}
\hline $\begin{array}{l}\text { Major criteria (1 point) } \\
\begin{array}{l}\text { Clinical suspicion of sphincter } \\
\text { of Oddi dysfunction }\end{array}\end{array}$ & Age $<50$ years and female \\
\hline $\begin{array}{l}\text { History of PEP } \\
\text { Pancreatic sphincterotomy }\end{array}$ & $\begin{array}{l}\text { History of recurrent pancreatitis } \\
\text { least one injection to tail }\end{array}$ \\
\hline Pre-cut sphincterotomy & Pancreatic acinarization \\
\hline$>8$ Cannulation attempt & Pancreatic brush cytology \\
\hline $\begin{array}{l}\text { Pneumatic dilation of intact } \\
\text { biliary sphincter }\end{array}$ & \\
\hline Ampullectomy & \\
\hline
\end{tabular}

preceding 1 week; (7) hypersensitivity to NSAIDs; (8) pregnancy or breastfeeding; (9) severe renal dysfunction; or (10) patients whom the doctor in attendance judged to be unsuitable for inclusion. Patients were randomly assigned to receive intravenous (IV) injection of $50 \mathrm{mg}$ flurbiprofen axetil with $20 \mathrm{~mL}$ saline (flurbiprofen group), or IV injection of $20 \mathrm{~mL}$ saline only (placebo group). The dose of flurbiprofen axetil was reduced to $25 \mathrm{mg}$ in patients whose body weight was $<50 \mathrm{~kg}$. Flurbiprofen axetil was injected IV immediately after ERCP while a patient was still in the procedure room. All patients received antibiotics (Sulbactam/Ampicillin $1 \mathrm{~g} \times 2$ ) and protease inhibitor (10 mg nafamostat mesilate). Randomization was performed using a random number table. Endoscopists and patients were blinded to the treatment group allocation. A total of 100 patients were randomized. ERCP was performed by 3 skilled endoscopists who each perform 200 to 300 ERCP procedures annually. We used a 15-degree backwardoblique angle duodenoscope with an elevator function (JF-260V, or TJF-260V; Olympus Medical Systems Corp, Tokyo, Japan). After the duodenal papilla had been viewed from the front, selective cannulation was attempted using a conventional catheter (PR104Q-1; Olympus) by contrast-assisted method. If 3 attempts at contrast-assisted cannulation of the pancreatic duct were unsuccessful, wire-guided cannulation (WGC) was attempted instead using a 0.035-inch guidewire (Jagwire, angle type; Boston Scientific, Boston, MA, USA). If cannulation by WGC was unsuccessful, precut was performed.

\section{Study outcomes}

The primary outcome of the study was the development of PEP, which was defined according to the criteria of Cotton et al. [1]. PEP was diagnosed if there was new onset of pain in the upper abdomen and elevation of serum amylase level to $>3$ times the upper limit of normal within 24 hours after ERCP, and prolonged hospitalization for $\geq 2$ days. The severity of pancreatitis was graded as mild when hospitalization lasted 2 to 3 days, moderate for 4 to 10 days, and severe when prolonged for $>10$ days or any of the following occurred: hemorrhagic pancreatitis, pancreatic necrosis, pancreatic pseudocyst, or a need for percutaneous drainage or surgery. The secondary outcome was serum amylase level at 2 hours after ERCP as a predictor of PEP.

\section{Sample size and statistical analysis}

We planned a prospective, randomized, placebo-controlled trial. Prior data indicate that the PEP rate among controls is 0.18 [6, 17]. If the true PEP rate is 0.04 with reference to previous studies $[6,17]$, we would have needed 182 patients to be able to reject

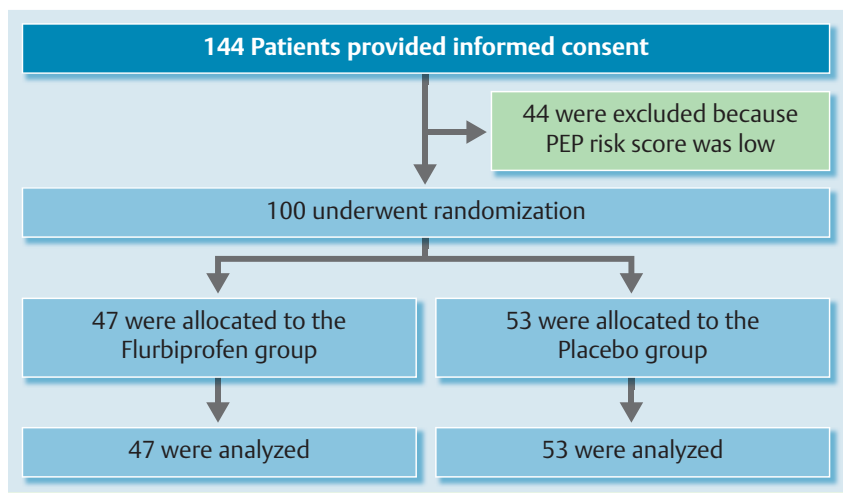

Fig. 1 Patient flow diagram.

the null hypothesis that the PEP rates for experimental and control subjects were equal with probability (power) 0.8. Type I error probability associated with this test of the null hypothesis was 0.05. We used an Fisher's exact test to evaluate this null hypothesis. Categorical variables were analyzed with $\mathrm{X}^{2}$ test, Fisher's exact test and Mann-Whitney U-test, as appropriate, while continuous variables were analyzed using Student's $t$ test. Risk factors for PEP were examined by univariate and multivariate analyses and calculated with odds ratio (OR) with $95 \%$ confidence interval (CI), using a logistic regression method. Statistical significance was set at $P<0.05$. Statistical analysis was performed using the Excel-Toukei 2010 for Windows (Social Survey Research Information, Tokyo, Japan).

\section{Results \\ $\nabla$}

\section{Patients and discontinuation}

From August 2013 to March 2015, a total of 144 patients were enrolled ( Fig. 1). In March 2015, we performed an interim analysis that has not been preplanned at the first 100 patients and recommended early termination of the study on the basis of the benefit of flurbiprofen axetil as compared with placebo for ethical reasons. A total of 47 patients received flurbiprofen axetil, and

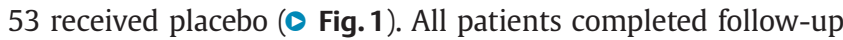
to the primary and secondary endpoints. Baseline characteristics and indications for ERCP were similar in the 2 groups ( $\bullet$ Table 2 and $\odot$ Table 3).

\section{Study outcomes}

The primary outcome of PEP occurred in 11 of 100 patients (11\%): 2 of 47 patients (4.3\%) in the flurbiprofen group and 9e of 53 patients $(17 \%)$ in the placebo group. The incidence of PEP was lower in the flurbiprofen group $(P=0.041)$. In addition, all instances of PEP in the flurbiprofen group were mild. However, in the placebo group, PEP was mild in 6 patients and moderate in 3 ( $\bullet$ Fig. 2 ). Absolute risk reduction was $12.7 \%$ and the number needed to treat (NNT) was 7.9. Relative risk reduction (RRR) was 62.4.

The secondary outcome, hyperamylasemia at 2 hours after ERCP, was observed in 22 of 100 patients (22\%): 8 of 47 patients $(17.0 \%)$ in the flurbiprofen group and 14 of 53 patients $(26.4 \%)$ in the placebo group $(P=0.109)$ ( $\bullet$ Fig. 2$)$. No AEs related to flurbiprofen axetil were reported.

The relative benefit of flurbiprofen axetil differed according to PEP risk score. With a risk score of 1 or 1.5 points, PEP occurred in 1 of $36(2.8 \%)$ patients and 7 of 42 (16.7) patients, respectively 


\begin{tabular}{|llll|}
\hline Characteristic & $\begin{array}{l}\text { Flurbiprofen } \\
\text { (N=47) }\end{array}$ & $\begin{array}{l}\text { Placebo } \\
\text { (N=53) }\end{array}$ & P value \\
\hline Age & 65.2 & 68.1 & 0.253 \\
\hline Female (\%) & $12(25.5)$ & $16(30.2)$ & 0.604 \\
\hline Younger age (<50 years) & $5(10.6)$ & $3(5.7)$ & 0.585 \\
\hline Naive pappila (\%) & $18(38.3)$ & $24(45.3)$ & 0.480 \\
\hline Clinical suspicion of sphincter of Oddi dysfunction & 0 & 0 & \\
\hline History of post-ERCP pancreatitis (\%) & $1(2.1)$ & $1(1.9)$ & 0.528 \\
\hline Difficult cannulation >8 attempt (\%) & $32(68.1)$ & $34(64.2)$ & 0.679 \\
\hline Pre-cut sphincterotomy (\%) & 0 & $2(3.8)$ & 0.529 \\
\hline Pancreatography>3 times (\%) & $24(51.1)$ & $24(45.3)$ & 0.564 \\
\hline Therapeutic pancreatic sphincterotomy (\%) & 0 & $1(1.9)$ & 0.952 \\
\hline Pancreatic acinarization (\%) & $12(25.5)$ & $10(18.9)$ & 0.422 \\
\hline Therapeutic biliary balloon dilation (\%) & $7(14.9)$ & $12(22.6)$ & 0.324 \\
\hline Ampullectomy (\%) & $4(8.5)$ & $3(5.7)$ & 0.869 \\
\hline Brush cytology (\%) & $1(2.1)$ & 0 & 0.952 \\
\hline Placement of pancreatic stent (\%) & $11(23.4)$ & $10(18.9)$ & 0.578 \\
\hline Sphincterotomy (\%) & $9(19.1)$ & $4(7.5)$ & 0.085 \\
\hline PEP score (\%) & & & $\mathbf{0 . 5 2 2}$ \\
\hline 1.0 & $25(53.2)$ & $33(62.3)$ & \\
\hline 1.5 & $11(23.4)$ & $9(17.0)$ & \\
\hline 2.0 & $10(21.3)$ & $6(11.3)$ & \\
\hline 2.5 & 0 & $5(9.4)$ & \\
\hline 3.0 & $1(4.7)$ & 0 & \\
\hline
\end{tabular}

Table 2 Patient characteristics 2at baseline.

Table 3 Indications for ERCP in the flurbiprofen axetil and placebo groups.

\begin{tabular}{|llll|}
\hline & $\begin{array}{l}\text { Flurbiprofen } \\
(\mathbf{N = 4 7 )}\end{array}$ & $\begin{array}{l}\text { Placebo } \\
(\mathbf{N = 5 3 )}\end{array}$ & P value \\
\hline Biliary stone & 12 & 17 & 0.472 \\
\hline Biliary tract cancer & 11 & 8 & 0.290 \\
\hline $\begin{array}{l}\text { Intraductal papillary mucinous } \\
\text { neoplasm }\end{array}$ & 4 & 2 & 0.566 \\
\hline Pancreatic cancer & 5 & 9 & 0.362 \\
\hline Chronic pancreatitis & 8 & 8 & 0.793 \\
\hline Ampullary tumor & 4 & 3 & 0.869 \\
\hline Others & 3 & 6 & 0.609 \\
\hline
\end{tabular}

$(P=0.047)$. The RRR was $83.3 \%$ and NNT was 7.2 . In contrast, in patients with a risk score $>2$ points, PEP was noted in 1 of 11 (9.1\%) patients and 2 of 11 (18.2) patients, and RRR was 50 and NNT was 11. There was no significant difference between the 2 groups $(P=0.500)(\checkmark$ Table 4$)$. Following multivariate logistic regression analysis, IV injection of flurbiprofen axetil was the only significant independent risk factor for occurrence of PEP (OR: 0.185, 95\% CI: 0.036-0.967) ( Table 5).

\section{Discussion}

$\nabla$

This study showed that IV injection of low-dose flurbiprofen axetil immediately after ERCP reduced PEP in high-risk patients. In addition, it may reduce moderate and severe PEP. However, flurbiprofen axetil did not reduce hyperamylasemia at 2 hours after ERCP. In this study, the NNT to prevent PEP in high-risk patients was 7.9. This was similar to a previous study of rectal NSAIDs use [6].

IV injection of $50 \mathrm{mg}$ flurbiprofen axetil immediately after ERCP reduced PEP in high-risk patients. There are several hypotheses regarding the mechanism of $\mathrm{PEP}$, and the promoters that lead to
PEP are not fully understood although the mechanisms are believed to be multifactorial $[4,18]$. One such factor is the patient's inflammatory reaction to irritation of the pancreatic duct, in which ERCP plays a role [19-21]. NSAIDs are potent inhibitors of phospholipase A2, cyclooxygenase, and neutrophil-endothelial interactions, all of which are involved in inflammation of the pancreatic duct. Thus, it is believed that NSAID administration may be of benefit in preventing pancreatitis. Several meta-analyses and randomized controlled trials have revealed that rectal NSAIDs are effective [12-15,22]. Most of those studies adopted a dose of $100 \mathrm{mg}$ of rectal NSAIDs, which is not suitable for Asian patients. So, Otsuka et al. reported that $50 \mathrm{mg}$ rectally diclofenac before ERCP was effective in Asian patients [17]. Although the efficacy of NSAIDs is reportedly dose-dependent [23], it is suggested that low-dose NSAIDs exert activity against PEP. However, NSAIDs were administered to all patients before ERCP in this study. Side effects are common with NSAIDs use [6], and the incidence of PEP in patients with 0 or 0.5 risk points indicated $1.9 \%$ (9/463) in our institution. Therefore, we considered that NSAID administration was unnecessary for low-risk patients. PEP risk score was decided after ERCP, we made a study design to lowdose flurbiprofen injection after ERCP. Furthermore, flurbiprofen axetil was considered easier to administer than rectal NSAIDs because of its intravenous route. This study revealed that IV injection of low-dose flurbiprofen axetil was an effective, safe and easy method for the prevention of PEP.

We administered nafamostat mesilate to the patients in both groups. Nafamostat mesilate has been reported to prevent PEP [24], so administration of a protease inhibitor is strongly recommended based on Japanese guidelines [25]. Therefore, it was difficult to design a study that would not include the administration of a protease inhibitor. The possibility exists that the effects of flurbiprofen axetil may be dependent on nafamostat mesilate. However, nafamostat mesilate was not considered a confounding factor because it was administered to both groups. 

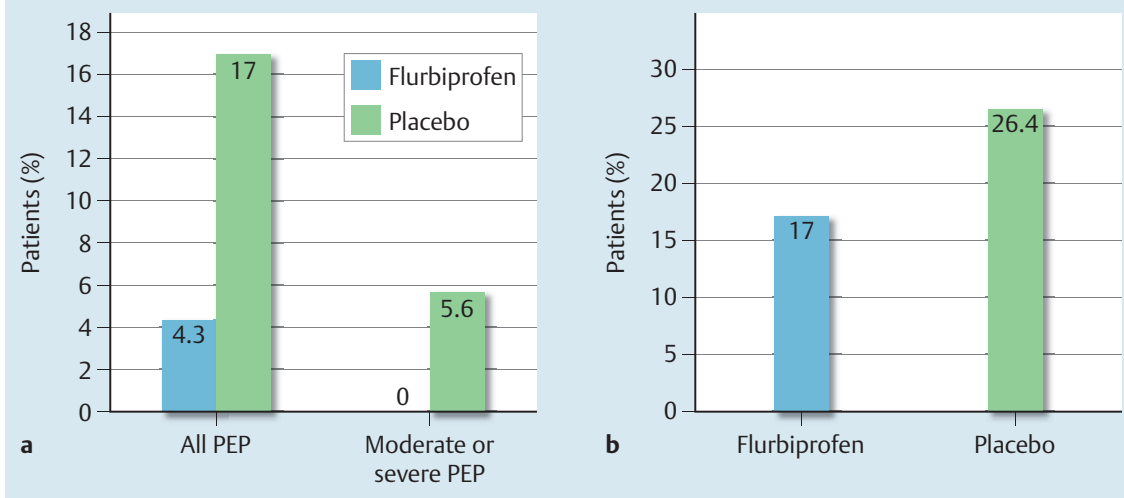

Fig. 2 Incidence of the primary and secondary outcomes. a Incidence of post-ERCP pancreatitis and severity in the two groups. $\mathbf{b}$ Incidence of hyperamylasemia in the two groups.

\begin{tabular}{|llllll|l|}
\hline & Flurbiprofen & Placebo & $\begin{array}{l}\text { Relative risk } \\
\text { reduction (\%) }\end{array}$ & NNT & P value & $\begin{array}{l}\text { Table } 4 \\
\text { effect. }\end{array}$ \\
\hline PEP risk score & & & & & \\
\hline Any score & $2 / 47(4.3)$ & $9 / 53(17.0)$ & 62.4 & 7.9 & 0.041 \\
\hline 1 or 1.5 & $1 / 36(2.8)$ & $7 / 42(16.7)$ & 83.3 & 7.2 & 0.047 \\
\hline$\geq 2$ & $1 / 11(9.1)$ & $2 / 11(18.2)$ & 50 & 11 & 0.500 \\
\hline
\end{tabular}

Table 5 Univariate and multivariate analyses for identification of independent risk factors for PEP.

\begin{tabular}{|c|c|c|c|c|c|c|}
\hline \multirow[t]{2}{*}{ Variables } & \multicolumn{3}{|l|}{ Univariate } & \multicolumn{3}{|c|}{ Multivariate } \\
\hline & Odds ratio & $95 \% \mathrm{Cl}$ & $P$ value & Odds ratio & $95 \% \mathrm{Cl}$ & $P$ value \\
\hline Female & 1.548 & $0.416-5.763$ & 0.515 & & & \\
\hline Naive papilla & 1.171 & $0.332-4.127$ & 0.806 & & & \\
\hline Difficult cannulation ( $>8$ attempt) & 0.890 & $0.241-3.281$ & 0.861 & & & \\
\hline Pancreatography (>3 times) & 1.343 & $0.382-4.723$ & 0.646 & & & \\
\hline Pancreatic acinarization & 1.382 & $0.334-5.718$ & 0.656 & & & \\
\hline Therapeutic biliary balloon dilation & 0.941 & $0.186-4.760$ & 0.942 & & & \\
\hline Ampullectomy & 1.383 & $0.151-12.690$ & 0.774 & & & \\
\hline Placement of pancreatic stent & 0.819 & $0.163-4.112$ & 0.808 & 1.042 & $0.191-5.684$ & 0.962 \\
\hline Sphincterotomy & 1.576 & $0.301-8.264$ & 0.591 & 2.533 & $0.404-15.884$ & 0.321 \\
\hline Flurbiprofen axetil & 0.217 & $0.044-1.063$ & 0.059 & 0.185 & $0.036-0.967$ & 0.046 \\
\hline
\end{tabular}

Flurbiprofen axetil did not reduce hyperamylasemia at 2 hours after ERCP. Hyperamylasemia is useful in the diagnosis of PEP, and LaFerla et al. reported that amylase at 2 hours after ERCP was useful for the prediction of PEP. Hyperamylasemia is thought to be caused by injury of the pancreatic duct or pancreatic parenchyma associated with ERCP. In this study, the specificity of hyperpmylasemia was $25 \%$ in the flurbiprofen group and $64.3 \%$ in the placebo group. The peak concentration of flurbiprofen axetil is reached 6.7 minutes after IV administration and the elimination half-time is 5.8 hours [26]. This suggests that, once the pancreatic duct and pancreatic parenchyma are injured by ERCP, the progress of pancreatitis could be prevented via the rapid anti-inflammatory effect of flurbiprofen axetil, thus reducing the severity of PEP.

Flurbiprofen axetil did not reduce the incidence of PEP in the patients who had a PEP risk score of $\geq 2$ points. In contrast, moderate and severe PEP did not occur in the flurbiprofen group. However, a result might change if numbers increase because there were few patients with a PEP risk score $\geq 2$. We hypothesize that the incidence of PEP in the group with PEP risk scores $\geq 2$ was reduced by increasing the quantity of Flurbiprofen axetil because the anti-inflammatory effect of flurbiprofen axetil effect is dosedependent [23]. Therefore, PEP cannot be prevented by flurbiprofen axetil in the group with PEP risk scores $\geq 2$ but severe pan- creatitis can be prevented. In the future, we plan to conduct a comparative study of low-dose and high-dose flurbiprofen axetil in patients with a PEP risk score $\geq 2$.

In this study, we attempted cannulation using a conventional catheter by contrast-injection cannulation methods. If this approach failed, we attempted WGC. WGC is the preferred technique because of its association with higher cannulation rates and lower risk of PEP, as reported by Cennamo $V$ et al [27]. However, subsequent studies have reported conflicting results. Nambu et al. reported that the incidence of PEP tended to be lower with the WGC method than with contrast-injection methods, although the success rate of cannulation was comparable [28]. Kawakami et al. and Kobayashi et al. reported that the WGC technique did not reduce PEP and did not improve the success rate of selective bile duct cannulation over contrast-injection methods. $[29,30]$. Therefore, we cannot conclude that WGC is superior to contrast-injection methods in terms of effectiveness and safety. For that reason, initial attempts at cannulation in this study were made using the contrast-injection cannulation method, with which the researchers were more familiar.

There were 3 limitations of this study. First, the study was conducted at a single center. Second, pancreatic duct stent placement was left to the discretion of the endoscopist. In this study, a pancreatic duct stent was placed where a guidewire remained 
following ERCP. Pancreatic stents were not placed where good discharge of the contrast agent in the pancreatic duct was observed. However, multivariate analysis showed that placement of the pancreatic stent was not significantly affected by reduced PEP ( Table 5). Third, interim analysis was not preplanned. As this was a single-blind study, we found that in the first 100 patients, administration of flurbiprofen reduced PEP, and an interim analysis showed its usefulness. Because PEP has been demonstrated to be a fatal complication, we stopped this prospective study. Further multicenter study will be required to determine the efficacy of flurbiprofen.

\section{Conclusion \\ $\nabla$}

In conclusion, IV injection of low-dose flurbiprofen axetil in highrisk patients is an effective, safe and easy method in the prevention of PEP.

\section{Competing interests: None}

\section{References}

1 Cotton PB, Lehman G, Vennes J et al. Endoscopic sphincterotomy complications and their management: an attempt at consensus. Gastrointest Endosc 1991; 37: 383 -393

2 Freeman ML, Nelson DB, Sherman $S$ et al. Complications of endoscopic biliary sphincterotomy. N Engl J Med 1996; 335: 909-918

3 Freeman ML, DiSario JA, Nelson DB et al. Risk factors for post-ERCP pancreatitis: a prospective, multicenter study. Gastrointest Endosc 2001; 54: $425-434$

4 Gottlieb K, Sherman S. ERCP and endoscopic biliary sphincterotomy-induced pancreatitis. Gastrointest Endosc Clin N Am 1998; 8: 87-114

5 Freeman ML. Adverse outcomes of ERCP. Gastrointest Endosc 2002; 56 : $273-282$

6 Elmunzer BJ, Scheiman JM, Lehman GA et al. A randomized trial of rectal indomethacin to prevent post-ERCP pancreatitis. N Engl J Med 2012; 366: $1414-1422$

7 Rabenstein T, Hahn EG. Post-ERCP pancreatitis: new momentum. Endoscopy 2002; 34: 325-329

8 Vandervoort J, Soetikno RM, Tham TC et al. Risk factors for complications after performance of ERCP. Gastrointest Endosc 2002; 56: 652 656

9 Whitcomb DC. Acute pancreatitis: molecular biology update. J Gastrointest Surg 2003; 7: 940-942

10 Gross V, Leser HG, Heinisch A et al. Inflammatory mediators and cytokines: new aspects of the pathophysiology and assessment of severity of acute pancreatitis? Hepatogastroenterology 1993; 40: 522 - 530

11 Mäkelä A, Kuusi T, Schröder T. Inhibition of serum phospholipase-A2 in acute pancreatitis by pharmacological agents in vitro. Scand J Clin Lab Invest 1997; 57: $401-407$

12 Murray B, Carter R, Imrie $C$ et al. Diclofenac reduces the incidence of acute pancreatitis after endoscopic retrograde cholangiopancreatography. Gastroenterology 2003; 124: 1786-1791

13 Sotoudehmanesh $R$, Khatibian M, Kolahdoozan $S$ et al. Indomethacin may reduce the incidence and severity of acute pancreatitis after ERCP. Am J Gastroenterol 2007; 102: 978-983
14 Khoshbaten M, Khorram H, Madad L et al. Role of diclofenac in reducing postendoscopic retrograde cholangiopancreatography pancreatitis. J Gastroenterol Hepatol 2008; 23: e11 - 16

15 Montaño Loza A, Rodríguez Lomelí X, García Correa JE et al. Effect of the administration of rectal indomethacin on amylase serum levels after endoscopic retrograde cholangiopancreatography, and its impact on the development of secondary pancreatitis episodes. Rev Esp Enferm Dig 2007; 99: 330-336

16 Elmunzer BJ, Higgins PD, Saini SD et al. Does rectal indomethacin eliminate the need for prophylactic pancreatic stent placement in patients undergoing high-risk ERCP? Post hoc efficacy and cost-benefit analyses using prospective clinical trial data. Am J Gastroenterol 2012; 108: $410-415$

17 Otsuka T, Kawazoe S, Nakashita S et al. Low-dose rectal diclofenac for prevention of post-endoscopic retrograde cholangiopancreatography pancreatitis: a randomized controlled trial. J Gastroenterol 2012; 47: $912-917$

18 Hofbauer B, Saluja AK, Lerch MM et al. Intra-acinar cell activation of trypsinogen during cerulean-induced pancreatitis in rats. Am J Physiol 1998; 275: G352-362

19 Messmann $H$, Vogt $W$, Holstege A et al. Post-ERP pancreatitis as a model for cytokine induced acute phase response in acute pancreatitis. Gut 1997; 40: 80-85

20 Karne S, Gorelick FS. Etiopathogenesis of acute pancreatitis. Surg Clin N Am 1999; 79: 699-710

21 Bhatia M, Brady M, Shokuhi $S$ et al. Inflammatory mediators in acute pancreatitis. J Pathol 2000; 190: 117-125

22 Elmunzer BJ, Waljee AK, Elta GH et al. A meta-analysis of rectal NSAIDs in the prevention of post-ERCP pancreatitis. Gut 2008; 57: 1262 - 1267

23 Giagoudakis G, Markantonis SL. Relationships between the concentrations of prostaglandins and the nonsteroidal anti-inflammatory drugs indomethacin, diclofenac, and ibuprofen. Pharmacotherapy 2005; 25: $18-25$

24 Yuhara H, Ogawa M, Kawaguchi Y et al. Pharmacologic prophylaxis of post-endoscopic retrograde cholangiopancreatography pancreatitis: protease inhibitors and NSAIDs in a meta-analysis. J Gastroenterol 2014; 49: 388 - 399

25 Working Group JPS. Post ERCP Pancreatitis Guidelines 2015. Suizou 30: $539-584$

26 Higashino M, Konishi $Y$, Kojima $H$ et al. 83 single and human blood concentration at the time of continuous intravenous administration transition and metabolism. Kiso to Rinsho 1992; 26: $3907-3921$

27 Cennamo V, Fuccio L, Zagari RM et al. Can a wire-guided cannulation technique increase bile duct cannulation rate and prevent post-ERCP pancreatitis? A meta-analysis of randomized controlled trials. Am J Gastroenterol 2009; 104: 2343-2350

28 Nambu T, Ukita T, Shigoka H et al. Wire-guided selective cannulation of the bile duct with a sphincterotome: a prospective randomized comparative study with the standard method. Scand J Gastroenterol 2011; 46: 109-115

29 Kawakami H, Maguchi H, Mukai T et al. A multicenter, prospective, randomized study of selective bile duct cannulation performed by multiple endoscopists: the BIDMEN study. Gastrointest Endosc 2012; 75: $362-372$

30 Kobayashi G, Fujita N, Imaizumi K et al. Wire-guided biliary cannulation technique does not reduce the risk of post-ERCP pancreatitis: multicenter randomized controlled trial. Dig Endosc 2013; 25: 295302 